\title{
The permanent and unavoidable construction of social
}

\author{
practices \\ Juan Jiménez-Albornoz. UTEM. \\ February 5th 2021.
}

\begin{abstract}
The question about social order and its transformation has been at the basis of theoretical discussion in sociology, and they are commonly thought as terms in opposition. In this paper we argue that the same process that generates social practices, that stablish order, is the one that transform them, and that this process is inherent to social life. In conclusion, it is unavoidable to construct social order and it is unavoidable its transformation: Social order is always in construction.
\end{abstract}

\section{Keywords}

Social theory, social order, social practices, practice construction, social change

\section{Introduction. The discussion of social order}

Social order is one of the most traditional problems in social sciences (and Benzecry, Krause, and Reed 2017: 8 in their recent review on social theory start with order as the first theoretical problem). Several theories had used it as their starting point (Elster, 1989; Giddens, 1984; Luhmann, 1995; Parsons, 1949). And even with theories that do 
not treat explicitly the problem of how social order is produced, they usually assume that social order exists, so in logical terms they begin with that problem as already solved, order is simply taken for granted (as Boltanski 2009, p. 85-6 says regarding institutions). Perspectives that do not use the word 'order', because in part has been associated with a specific conception of it (structuralist, unitary and so on) will replace it with an analogous one: pattern (for instance, Dépelteau, 2008, 2013, in his examination of recent relationalist thought; or Manzo, reviewing analytic sociology Manzo 2014: 9) or equilibrium (see for instance Hindriks 2019). That some level of social order exists is something we all, as participants in social life, are aware in practical terms.

Since it is a traditional issue, some traditional conceptual relationships also exist in this regard. The clearest is the opposition between order and change. Although this opposition was not born with Parsons, it can be said be one of his most enduring legacies and it is very pervasive in sociological theory (Gonnet, 2015): The dynamics can produce order are not the dynamics that produce change, to explain order you need to postulate processes that stop change, social transformation operates through breaking through order (see for instance Archer 1995 or White 2008; earlier the views of Dahrendorf). Recently Brandmayr (2018) has shown how the general opposition between order/conflicts operates in the sociology of science and in the concepts used by participants in controversies. More in general we can oppose the idea of an settled order against a more fluid reality: traditional sociology can be criticized for its focus on established order and so for its denial of processes of becoming (Latour, 2005) and we 
can separate the properties needed to understand the origin and formation of some element of social life from the ones needed to explain their continuing causal powers (Rutzou \& Elder-Vass, 2019).

That conceptual scheme (the distinction order/change and the idea that they need different dynamics to be explained) is, in some sense, strange. At least in formal terms and remaining inside the idea that order and change are opposed, any theory of social order is a theory of social change. Any process that is a condition of social order gives a ready explanation of change: change happens when that condition is not held. Even more, is enough to think of social orders in a dynamic sense for the opposition order/change to diminish. Stable social dynamics can generate a trend (a movement), and that trend changes things: Then, to stop change you need to stop the trend and that means to transform that dynamic ${ }^{1}$. It has been remarked also that 'disruption is essential to any interactional order' (Tavory \& Fine, 2020: 372). Order and change, then, appear mutually involved and not opposed: the problem of order is an examination on the dynamics of social patterns. In the end, to oppose chance (or conflict) to order implies to put outside order a large amount of social life and it does not allow to recognize that in all events [including ones disruptive to order] there is in play social structures' (Gonnet, 2018: 69)

\footnotetext{
${ }^{1}$ This is not an 'abstract' theoretical issue. Several years ago, the author of this paper was involved in a research on community perceptions on their own places. One theme that appeared repeatedly was the desire to stop change, that things remained as they were. But, as the research team discussed, to do that, those communities could need to change the dynamics that produces those trends
} 
We can observe at this point that the difference order/transformation several times in sociological thought has been joined to another difference: the structure/action distinction, and this will help us to understand the pitfalls of that conceptual scheme. Under this conceptual scheme, one that is widely shared (both Parsons, 1951 and Bourdieu, 2015: I, 370 used it, to mention authors in opposition) when people act according to the institutional order -when they incorporate in themselves the social rules- what it follows is only a reproductive dynamic. Then, when those distinctions are joined, only 'real' action is thought as transformational (Dubet, 1994; Touraine, 2013) and it is separated from 'reproductive' action. 'Action is fresh when it overcomes the inherent lethargy of social life' (White, 2008: 279), but in contrast, action that simply reproduces social structure is 'uneventful' or trivial (for a criticism, see Moore 2011).

This conceptual scheme hides the effort and activity that even reproduction needs. The reproduction of social order to be effective requires attentive behaviour by the agents, it does not simply happen. To use the clearest example: the reproduction of a language operates through the skilful enactment of it by their speakers. This overlook of the action character of reproduction is shown in the reception of Bourdieu: A common criticism is that he is 'structuralist' and he does not gave any strong space for action, and for change (Aguilar, 2008; Atkinson, 2010; Martuccelli, 2013; van der Berg, 1998), but at the same time Bourdieu stresses the practical and strategical character of reproduction, hence, even if he falls also in the pitfalls of the scheme we discuss, there 
is space to point out that reproduction is not something simply given (Frank, 2012; Nieto Calleja, 2012; Swedberg, 2011)².

In sum, we can doubt if the separation between 'real' action and reproduction is adequate as a depiction of action and we can wonder if reproduction can be 'merely' reproduction. Any action represents a modification of the world -some resources are used or some information is shared-, and that makes doubtful that the social world could remain without any change, and to conclude that those modifications could remain small requires more analysis. The historical record shows a lot of instances where efforts to maintain the situation generated changes or where even the continuous reproduction of a practice generate difficulties for its permanence (depletion of resources being the clearest example) ${ }^{3}$.

Given all those problems maybe an approach that does not oppose order and transformation, the behaviours that reproduce and the behaviours that transform, is interesting to develop. It is, at least what this paper attempts to do; and we will start with a discussion on the notion of social order.

2 If the formulations of Bourdieu in this conceptual space are sufficient can be discussed. The '[(habitus) (capital)]+field=practice' formula (Bourdieu, 1979: 112, author translation) gives space to agency, but it is not a 'creative' space (Cristiano, 2011; Joas, 1992). And in his classes in the College of France, Bourdieu stresses the idea of habitus as incorporation, embodiment, of social processes (Bourdieu, 2015: I, 238-341): then action is not a mechanistic, rule-bound process, and you can conclude no mere reproduction, but if that 'not mere' is enough is not clear.

${ }^{3}$ Only as illustration. In order to ensure the reproduction of the Roman political system and domination by the optimates, Cicero developed a theory of the res publica devised to justify the extra-legal punishments for the 'disloyal' opposition, showing how reproduction needs action; and that theory was afterwards used by the emperors to justify political murders and then to end the republic, the chief thing that Cicero tried to avoid, showing then how reproduction actions can generate transformations, see Moatti 2018, Chap. 5 and 6. 


\section{Types of Order}

A social order is a form in which the complexity of interaction is simplified. An interaction set of maximum complexity is one where there is no limit or pattern to the alternatives ('everything is equally possible'), and then to simplify imply a reduction of the alternatives (or at the very least, a distribution from more to less common alternatives). In real social life there is not a predefined set of alternatives (since all players have the ability to create new ones), so 'there is no limit' implies more than a simple no reduction of given alternatives. From the practical point of view (from the point of view of the agent), a situation of maximum complexity is one when any alternative an agent can distinguish is equally feasible. Order is some way a selection to generate a lesser set of feasible alternatives and that expectation ('not everything is equally possible') is then crucial to any kind of social order, even more crucial that actual behavior (Gonnet, 2018).

The simplest way to do that reduction is to stabilize relationships: Ego can do any kind of action, but it selects alters, and do that in a recurrent manner. In this sense a social network is a kind of order: it means that diachronically social reality is stabilized. The set is simpler since the description on time $t$ is similar to $t+1$.

Another way to stabilize is to simplify the kind of actions that ego makes when interacts: The contents or the mode of interaction are stabilized. This is the manner that 
corresponds to social practices. In particular, we will define social practice as a specific kind of order under this manner: When agents select some possible coordination with alters (they do not do any possible action) and that selection corresponds to an identifiable role or position (I do such actions with such kinds of agents). The social world is simplified because ego do not distinguish every single partner, but it makes a reduction to a smaller set of positions and is further simplified because for each role there is an established set of alternatives. The more clear cases, because then both positions and behaviours are more clearly established, are formal games or rituals: A game of soccer define some positions (goalkeepers, players, referees) and what each of them can do regarding each other is also established; a marriage ritual do the same. More common practices are not that formalized, but even if positions and actions are less defined, they exist at some degree. After all, we can recognize and know what actions are preferred in situations like shopping, going to classes, talking to friends, there are conflicts about interpretation, but we are far from 'everything is possible' situation ${ }^{4}$. Even if conduct itself do not follow that expectations, those exist and they can be used to guide behaviour: they can generate patterned reactions -'this is not shopping, we should then behave this way' or even 'then we are not shopping' (conversation analysis has shown how in interaction even deviating from script generates particular patterns, see Schegloff, 2007, specially chaps. 5 and 6)

\footnotetext{
${ }^{4}$ Those types of social order do not represent a complete set of strategies. It can be argued that collective identities, where actors simplify the variety of agents by dividing them in groups, are also orders in the sense we are using here. Regarding those groups there are not specific actions to do, but the identities are used to select some alternatives as feasible or not
} 
The difference between those forms is primarily analytical. It is evident that in every concrete social setting we will see both social practices and social networks at the same time, and they will be mixed. One relevant difference is whereas in a social practice the specific person we interact is less relevant (every seller is alike as a seller, every street preacher rather the same), in social networks that specific identities are paramount. And we can see how those dimensions mix: We will be friends with A and not B, so in that regard we operate in social networks terms, but what friendship is about (what things friends can ask or expect of each other) is more general, and then we can think of friendship as a social practice.

There are not only several ways in which order is produced (complexity is reduced), but we can say also then that there is not a single problem of order. This from two considerations.

Using the nomenclature devised by Elster (1989) we can distinguish between a Macbethian problem and the Hobbesian problem of social order. In the first, order is understood as stability; in the second, order is understood as peace. Now, a stable social setting is quite different to a relatively peaceful one. War can be thought, precisely, as a non-cooperative social practice, and then as a stable manner to behave: in a given social settings combatants know what to do and what to expect ('this is what we do when going or preparing an offensive, managing a siege, dealing with casualties' and so on). A lot of discussion on the Hobbesian problem of order is about the development and stabilization of cooperation (and there is a giant literature on, let say, how cooperation 
emerges in that much studied setting of prisoner's dilemma). Now from a 'Macbethian' perspective, a lot of those studies start from an already ordered situation: Partners are already in an established setting (with rules of interaction and payoffs) that is stable in time (for instance, in all studies of repeated interaction). Cooperation is, in some sense, a derived problem from the most basic issue of coordination, and how agents manage to develop some stable social settings appears to be the most basic issue.

Coordination settings are multiple and the same act by ego that can be used to coordinate with some alters can disrupt coordination with other alters. It can be pointed out that it is not difficult to think situations in which coordination between some agents is the mean used to resist to coordination exigences made by others. Then, when empirical orders are analysed it should be about concrete settings and interactants, order is always situated in this sense: is order under a specific point of view, and not in terms of a general and abstract problem of order. Even when the question is about the dynamics of social order in general the above consideration should not be forgotten. We should not think about the production of social order, but of social orders.

\section{Social Practices.}

In this paper we will focus on the dynamics of social practices. The processes we will discuss are not necessarily the same that generate other kinds of social order; and this 
is a reminder, again, that social order should not be thought as a monolithic issue. We will start defining social practices.

Network of roles A social network in which two agents in structural equivalent positions could be replaced without affecting the behaviour of the other actors in the network ${ }^{5}$.

Social Practice A set of interactions locally stable that is formed by a network of roles in which the content of the interaction is also stabilized.

The first definition follows the idea already mentioned that in a social practice what matters is not the concrete actor but rather its 'position'. The second one adds the idea that we can talk about a social practice when that structure achieves some degree of stabilization (we add locally to emphasize that we can say that an order is operating referred to specific spaces: the social practice of friendship operates in this manner in this setting). The definition stresses that the stabilization in a social practice operates regarding positions and the actions associated to those positions.

Using this definition, we will argue the chief results of this paper: That the production of social practices it is characterized by two elements. First, that is unavoidable for actors -given the abilities and traits of actors it is impossible for them not to generate social practices. Second, that the process of generation of social

\footnotetext{
${ }^{5}$ The idea of role is based on the idea of substitutability, see Borgatti, Everett, and Johnson (2013: 208). Our definition is equivalences used by the agents, and not only something acknowledged by observers.
} 
practices is unending and given that it is impossible to guarantee the perfect continuation of that order.

In the next section we will argue some statements that will allow us to defend those results in the subsequent section.

\section{Generating social interaction}

In the real social world, there is always some social practice established, and it is among the chief results of this paper an explanation of the fact that some level of social order is always present. Now, in order to analyse how they emerge and to defend that idea it will be useful to not assume that existence. If we can show that social order inevitably emerges even in that case, then the permanent existence of social order, its ubiquitous character, can be better understood.

We will start then with some arguments about the minimal traits of the agents and the interactions that they develop. I want to stress that those are minimal traits that are sufficient in themselves to produce social order. They are not all the relevant traits needed to understand social order and practices, and we are not denying the other traits could be sufficient to produce them. To understand social processes, for instance, the fact that human beings are emotional beings (Epstein, 2013) or that they are beings 
of flesh and bone (Joas, 1992) ${ }^{6}$, or that human social worlds are built not only on interaction with each other but interacting with material reality (Chuaqui, 2011; Latour, 2005; Skvoretz, 2002) are relevant; and any attempt to explain social life that forgot those traits will be inadequate. As Latour (2005) establishes human social life can be more stable than other primates precisely because its deep interaction with materiality. In this paper we are not trying to understand comprehensibly social life, but only trying to explain some of the characteristics of that life; hence, a strategy of minimal traits is useful in that regard.

The traits we will give to the agents in the model are basically three: They are able to make distinctions, they are able to value those distinctions ad they are able to remember. Those abilities are close to the DBO model of Hedström, 2005 (or see also Fehr and Gintis, 2007), where agents have desires, beliefs and opportunities; and it is close also to a view where social actors can be seen as Brownian agents, with internal states, ability to store information and interact (see Castellano, Fortunato, and Loreto, 2009: 8). The reason we use a formulation based on distinctions is that in order to do anything (learn, have beliefs, even be able to notice -or not- opportunities) the basic operation is to be able to make distinctions.

The first proposition we want to argue is that agent's capabilities are at the same time finite (they have a throughput limit) and universal (they can be applied to any object or

\footnotetext{
${ }^{6}$ The relationship of social processes with biological traits can be understood with reference to an historical instance. To understand what levels of work effort were attainable at the time of the Industrial Revolution, to know how many calories workers did eat is relevant, since the human metabolism put some requirements about it, see Voth (2001)
} 
situation). Both elements should be understood in relation. There is no external limit to where those abilities can be applied, even when there is always some limit on how those abilities are used. It is important to acknowledge this double circumstance, because is not uncommon to think about agent limitations as if they were the same. In the models of bounded rationality or agent models (Epstein, 2007) the basic idea, the one that differentiates those models from rational choice ones, is that agents can not make all possible calculations and every single ability modelled has some limit (in storing information or number of interactions or number of alternatives), but it is not taken on account that social agents can act over any element, in other words they have the ability to change the rules of interaction or even to create new alternatives not envisioned in the model. The processual limits are thought as including applicability limits. Rational choice models actually invert the limitation conditions, and they act as if agents are procedurally infinite (they can make all calculations they need for instance) but they have limitations on where they apply those abilities: A game theory model usually will postulate the rules of the game and the set of possible alternatives and agents do not have internally the ability to change those rules; or more in general agents can have preferences abiding for the most strict rationality requirements, but they do not have, for instance, preferences on preferences. In this sense, we should remember that there are preferences on preferences or learning about learning, and even mixings: people can have preferences about learning or to learn about preferences ${ }^{7}$.

7 At some level, part of economics can be seen as a activity dedicated not to understand human behaviour, but as an attempt to develop a social technology: the rational model of action, as Callon 
The second proposition we want to stress is quite trivial in itself, but crucial in its consequences: agents are able and require learning. Given the centrality of distinctions in this approach, we will define learning on these terms: To learn something is be able to link and associate new elements in a stable manner (for instance, to learn that apples are sweet imply to link several elements under the label 'apple', link others as 'sweet', and to link those labels, and at least some of the linkages are, for the agent, new; not available before).

Now, for the argument. Since agents make distinctions, and since their abilities can be applied to any element, then it follows that agents are able to make distinctions on distinctions. So, they are able to make a distinction that associate several distinctions, or to be precise sides of those distinctions (following the example before, from the distinction 'apple/not apple' and from 'sweet/not sweet' they are able to associate the sides of those distinctions 'apple goes with sweet').

To achieve learning we need that those linkages are stabilized (we could not say that someone learned that 'apples are sweet' unless that person recurrently use that distinction). Now, we know that actors are limited in the throughput of any ability they have. To link distinctions in a stable manner (to have representations) is to simplify the world: The agent does not face a world in which any element can link to any other

(2007) has emphasized with his idea of 'performativity' and more in general in its perspective about how an economy is enacted (Çalıkan \& Callon, 2010). We can observe that Nussbaum (2001) has shown that it was to impose a new practical vision of action that Plato developed his 'initial' model of an unified rational actor-as a way for people not to accept the conflict of values and to be able to 'calculate' what action was best, the same unifying perspective on action of all rational models. In this sense, the very activity of economics show that actors abilities are unlimited in their applicability 
element, but that A (apple) is associated regularly with (B) sweet. To act in the world without simplifications overwhelms the agent (that in practical terms is what means to have throughput limitations), and then it is simply impossible for actors not to have stable linkages in the new associations -in other words, the actor is able and require to learn to be able to act in the world.

The third proposition we will argue is that for every agent, other agents are not completely predictable and are perceived as separate decision agents. If the agents are limited, then their ability to know (to learn about) the decisions of other actors is also limited: alter is always relatively unpredictable. Since the world is always more complex than the abilities of an agent then there is always the possibility that alter uses a distinction or generate an action that it is not among the space of possibilities envisioned by $\mathrm{ego}^{8}$. In those conditions, no actor has the capability to take on account all the possible alternatives (of all combinations and possible ideas).

Besides that, actions have effects -by the mere fact that an action is, by definition, something that produces a modification in the world. Now, since agents are limited in their throughput then actors can not foresee all effects of an action; then, the world always include things that the actor do not know. Even more, given that effects are understood by an actor when the actor can distinguish them and since the actors are unable to know the entire set of possible distinctions (because they are limited and that

\footnotetext{
${ }^{8}$ The condition of predictability is to restraint the options of alter: the reduction that a researcher makes in a model, in reality, as Albert Hirschman said, is only through repressive governments that predictability can be enacted (Hirschman, 1992: 53)
} 
set is quite greater than their abilities), it follows that this ignorance is necessary, not only probable. And now, alter always has open the possibility to distinguish an effect that ego, who acted, did not observe. That means that ego can not think of alter's actions as mere consequences of ego's action, there is always the possibility that alter adds something more, something new.

The statement requires something else besides: that an agent acknowledges other agents qua agents. The agents can interact and they can communicate ${ }^{9}$, and since those capabilities can apply to any situation, then we know that an agent can act on the action of alter and to distinguish their communications. From that, an agent can infer that alter is an agent that can act and distinguish, and then to conclude that it is in an agent ${ }^{10}$.

The next proposition is a consequence of the above: each interaction generates possibilities for new interactions. This means that the interest of any agent for coordination is permanent, there is no point at which there is no possible further gain from coordination. As before, we start with the statement that actors are limited, and then they can not foresee their future needs or learnings. This means that from ego point of view alter is always a possible source to learn or to fulfil needs. That means that there is always a possible source of interest in continuing interacting. Given that agents know that other agents are separate decision agents that is even more relevant:

\footnotetext{
${ }^{9}$ Since they are agents they can act, and if they can act and they do not have limitations about where those abilities apply, they can interact. We already said that they can distinguish, and for the same reasoning they can distinguish about the distinctions on others and interact about them -and that is communication

${ }^{10}$ It is possible to argue in the inverse: that from that equivalence in complexity it can be derived that agents can not mutually predict themselves (Albin, 1998)
} 
they are aware that alter can do actions and learn things that they are not able to do or that they do not know. Given that the set of all possible effects is unknown, in every interaction can develop new learnings (as a consequence of interacting with alter, ego can have some new idea that alter did not had): The interaction in itself produces possibilities of new knowledge of interest for the agents. In more concrete terms, we can notice that one of the features of conversation and argumentation there is new possibilities to continue it, to further inquiry about a point (Meyer, 2013:112,181) ${ }^{11}$. So, in general a given interaction generate new possibilities for new interactions.

\section{The production of social practices}

Given the previous statements, now we can develop the central arguments of this paper.

The first is that agents generate automatically social practices. In order to produce social practices it is needed that appear a set of typifications that are connected among themselves, in a way that is formed a network of roles, and that process generate a stabilization of said network. The proposition entails that this process is automatic in social life: whenever agents interact those process will develop.

Let us suppose a set of agents interacting. Those agents will learn at different speeds and different things about that interaction: To achieve that $\alpha$ do X ego needs to use such alternative; only with $\beta$ but not with $\gamma$ ego can coordinate this action and so on. To learn

\footnotetext{
${ }^{11}$ In some sense, ancient scepticism, Sextus Empiricus for instance, is a meditation on the impossibility to close a conversation: 'and the sceptics are still investigating' (Sextus Empiricus, 2000: I,i,2)
} 
imply a stable link between distinctions, and given that a distinction implies actions ${ }^{12}$, then each agent will stabilize their own behaviour. Given the limitations of the agents, said stabilization will help to manage the world (as Luhmann, 1995, says: the environment is always more complex than the system). Those learnings can spread by communication. Then we have a network with certain level of stability.

In order to generate a social practice, in first place, it is needed that those stabilizations are transformed in typifications: Agents go from 'I can coordinate action $X$ with $\alpha$ ' to 'I can coordinate actions of the type $X$ with agents of $\alpha$ type'. Since agents continue to learn, and those learnings can be on other agents and actions, then it follows that they can make distinctions on those; and those distinctions are typifications.

Those are not yet common typifications, and a social practice need those: that those typifications are not used by a single agent but they are known and used by the rest of the interactants. Each type can be understood as a proposal to achieve co-ordinations (ego can tell some alter: if you want to coordinate type $X$, then you can go to agents of $\alpha$ type). If those classifications generate co-ordinations that work, those classification will tend to spread (they will be copied by agents over others, so more successful coordinations will be preferred when agents deem it useful to achieve the outcomes they look for). This process can be speed up by the fact that since agents can act on interactions, they can try to influence that alters use some classification. Since several

${ }^{12}$ In this paper we will not develop the argument fully, but the basis is the idea that agents make distinctions to learn, and that is an action; and making an action imply to make distinctions (for an agent the distinction between doing action $\mathrm{X} /$ not doing action $\mathrm{X}$; acting on $\mathrm{X} /$ acting on $\mathrm{Y}$ and so on). Then, actions and distinctions are always involved in each other 
agents can do that, with different classification, there could appear a classification competition. In this case, some will start to expand more, and that expansion is in itself a motive for further expansion (coordination is easier when an agent uses a commoner coordination and expectations are then aligned). That allows to generate a common typification.

In a given context, agents know that to coordinate $X$ they expect to do it with agents of $\alpha$ type. Now, the same process can be replicated in other situations. Then, the same $\alpha$ will further continue the process: that to achieve the coordination $Y$ they expect to do it with agents of $\beta$ type. Since all of this can be observed by the agents, so the expectations are conjoined. In a determined context, it happens A: That to achieve coordination $X$, that is done with agents of $\alpha$ type; and $\alpha$ agents coordinate $Y$ with agents of $\beta$ type. Since those agents are typified, then what it matters is the type, not the particular agent involved. The description does not change when changing concrete agents, so we are under a network of roles. And all the learning and stabilization processes already discussed appear again, so those dynamics create a stabilized network of roles, a social practice.

The previous argument is clearly not a proof of the statement. The discussion has not taken on account the diversity of interests (beyond the generic interest in coordination) or the level of repeated interaction needed for these processes to start or spread, neither we had discussed the effects of superposition of ego networks (the commonality in the reference group needed for the inference of 'this typification is 
common' and for that inference to be in itself common), the fact that agents will not reach the same inferences, or what factors affect speed or spread of the process, the relationship with social network dynamics (see for instance all the recent literature on complex contagions Centola 2018; Centola and Macy 2007; Manzo et al 2018) and several other traits of interaction that are relevant in the process of generation of social practices (and the fact we had not taken them on account in this paper does not mean that this approach is not able to include them). Nevertheless, we feel that these complexities could not change the outcome: that agents in interaction will generate social practices.

This is due to the fact that the argument we had used is based on a very general characteristic of the agents: That agent need to make typifications in order to act, that without simplifying the world they are unable to conduct themselves in the world. Given that, the traits we had not considered can have several consequences on the process, but it is unlikely that they could change it. The social practice emerges from that typifications because the interactions generated are again the object of processes of observation and communication, and since those processes also can be used to simplify the world ('when in Rome...') they will be used to do that: they have an incentive to use any kind of signal to simplify their interactions (so, even in settings that intend to be 'meritocratic' they will use as signal what others do and select, and even more since they know that everyone do the same, then they can be evaluated on using that information, reinforcing the dynamic, see Correll et all, 2017). Those processes are enough to generate a concatenation of typical action among agents also typical. The 
main point is that agents can not avoid simplify the world, and they are interested on that; and given this, interaction processes generate social practices.

Regarding this first main statement, we can first observe that these typifications are not necessarily rules, the idea that a practice is constituted by rules (Giddens, 1984, 1993; Winch, 1958) is not warranted. The idea of following rules present some problems, it is not clear how an agent can determinate that it is following a rule, and the idea of tacit rules (as Bourdieu 1990, 2000 has been interpreted) do not solve those (see, Gerrans 2005) We referenced Bourdieu, but he actually rejected the idea that habitus is a rule following structure, and more to the point that concept was devised precisely to avoid the idea of a rule: 'they guide their action in the manner of a logical need (...), but without imposing to them as if they applied a rule $o$ as if they submitted to the verdict of a kind of rational calculation' (Bourdieu, 1994: 223, author translation) ${ }^{13}$. The model of rule following (allowing for exceptions) has been taken from language, but in that field, there are also doubts about understanding language use as rule based (Seidenberg \& Plaut, 2014). Given that, we only pose that there are typifications -some way in which agents are able to reduce the complexity the world they face- without discussing here the specific mechanisms that allow for it. The idea of an 'ordered' behaviour that do not operate through rules is an old one, and it has been always difficult to precise and define: From Daoism (Graham, 1989) or Aristotle's practical reason (Aristotle, 2009, 1140ab, 1142a) to more recently Searle (1995, Chap.

13. The original quote here: 'il guide aussi son action à la façon d'une nécessité logique (...), mais sans s'imposer à lui comme s'il appliquait une règle ou s'il se soumettait au verdit d'une sorte de calcul rationnel' 
6) with his background abilities and the already quoted Bourdieu, there are several variations on the theme of the insufficiency of rule following ${ }^{14}$. Those discussions have methodological consequences, as Flyvbjerg (2001); Flyvbjerg, Landman, and Schram (2012) has noticed.

A second comment is that the process of expansion of a typification has been described under quasi-utilitarian considerations (a typification expands when it 'works' for the agent), but the pure motivation to imitate can be also be a powerful force for that expansion in itself. Haun, Rekers, and Tomasello (2014) have shown that human children when they already had acquired some behaviour that 'works' change their behaviour if they see alters doing other actions, but simians only change behaviour if they do not have an already established behaviour. In general, we already had pointed out the interest that other agents have for any individual actor, and hence that agents will observe and try to learn about others. Collins \& Evans (2014, p 4-5) has shown the relevance of interactional expertise and in particular the knowledge about the practices of other agents, and even if the particular mechanisms discussed may not be correct (see Arminen, Segersven, and Simonen 2019 for an empirical criticism), the general idea that agents have expertise about beliefs and behaviours of other agents remains grounded.

14. Even more, we can see the intuition of this insufficiency when we compare Kant's ethical theory, based on formalizable maxims (Kant, 2013) and his analysis of the reflective judgements, an objective affirmation that is not a simple deduction from principles (Kant, 2012) 
One last remark. We had not discussed in detail the fact that agents do not necessarily infer the same things from situations or that they can differ in what they regard as the 'same' situation, the basis for a typification process; more in general, they differ in the schemes they have and that is not erased when they develop common typifications (Wood, Stoltz, Van Ness, \& Taylor, 2018). And given that agents can not predict what other agents can do with a given information this is a relevant dynamic. On the other hand, since agents if coordinating are interested in creating a manageable common typification this situation is also a problem for the agents, and they had devised some mechanisms to try to ensure mutual understanding (Schegloff, 1992, 1996). The operation of these mechanisms can help the development of social practices, but they show that the stability of those practices can not simply taken on granted; a consideration relevant for our second main result.

It is not only impossible to avoid that social practices are created, but also it is impossible that a social practice generates depending only on itself the conditions of its reproduction. The argument is quite simple: The processes described in the previous statement do not have a determinable end. Actors can not eliminate the possibility of new learnings and, specifically, that alter continue to learn. Given that, it is always possible that emerge new stabilizations, typifications and typifications proposals. Actors can not eliminate the possibility of changes on the basis of interaction (the attraction of the resources involved, the relevance of knowledge and information shared about them, the value of the beliefs involved, the control exercised on elements 
and so on $)^{15}$. In general, the consequences of actions or interactions are not completely predictable or controllable, and from them it is always possible to generate new practices or to modify them.

The main consequences of the previous statements are that (a) it is not possible to avoid that social agents create order, and that (b) it is also impossible to guarantee its reproduction without change. Social order is, at the same time, omnipresent and changing. The process that create and generate social order are the same processes that destabilize $i^{16}$

All those processes had been analysed as if they were automatic ones. It is clear that not all creation, continuity or transformation of social practices is of that kind. Games can be designed from the beginning, and spreading is not only being about recognizing types of actions or types of agents, but also about copying and using a given ruleset; or even a practice originally simply 'grown' can be -when stabilized- copied in full (for instance, copying an institutional structure that originally developed without design, as it has been argued Meiji Japan did in the late XIX century). The processes we had depicted are not all the mechanisms in which social practices are developed, but they are the most basic ones and they operate incessantly in the background of social life. In this sense, they are inescapable.

${ }^{15} \mathrm{~A}$ social practice can be based in the use on a resource, but if the value of that resource changes because a development outside the practice, the entire context of interaction can change, and affect the continuity of the practice. When iron tools appeared several practices, based on the relative scarcity of the materials used in bronze tools, lost relevance

${ }^{16}$ Castoriadis has remarked the same in his examination of ancient Greek thought: that an existence is destroyed by the same principle that generates it (Castoriadis, 2006, Seminar of February 16th, 1983) 
It is important to notice again how relevant is the open nature of social life -that agents always have the ability to develop new alternatives. In closed models, where the researcher defines all possible course of action, it is possible to find some kind of equilibrium ${ }^{17}$; so in a long term it can be expected that outcomes will converge to those equilibriums. Now if relationships or payoffs are not stable, if the situation can be changed due to the actions of the agents (new alternatives of action be devised), then that does not happen: any convergence or any equilibrium is always temporary (and even unreachable: if convergence speed is slower than changes in structure that could affect if equilibrium is reached at all or even if that equilibrium works as an attraction basin). That the social world is open, and that agents have the ability to develop new behaviours and alternatives, is crucial for a thorough understanding of social life.

\section{Conclusion}

The two main statements argued in this paper try to show that is fruitful to escape from perspectives that simply oppose order and disorder. The idea that process that generate order are necessarily different of those that transform that order is insufficient. Since we had not analysed all processes, we can not forbid the possibility of some order generating processes that are unable to generate dis-order. What we can state is that there are some processes that are both things. That the generation of new

17 Those equilibriums can be stochastic (Young, 1998) or the distribution of outcomes can reach
equilibrium even if strategies themselves are not 
learnings about the world, the typifications of action associated, both born from the need to simplify the world, generate a social process that produce order, and that this same process, since it does not have an end as such, is sufficient to destabilise that very order. Also we can see how the idea that reproduction is almost a 'inertial' force, or that nothing happens when social life reproduces itself, is incorrect: If an order operates through a process in which regularities are acknowledged and produced, then since that process is without end, and given that actions are interventions in the world, and as we had argued agents are unable to know or control the consequences of those, then any action -even 'inertial' ones- can be the source of transformations.

As we pointed out, the arguments of this paper only explore a small part regarding the processes of construction/transformation of social orders. There are a lot of further complexities that we had not developed, other relevant process, and other kinds of social orders. In all those processes the perspective used in this paper (agents limited in throughput but not on space of application and the dynamics that this generates, the permanent possibility of new alternatives) can be useful to think about them.

This papers states two limits, two impossibilities, in social life. In the first place, it is impossible that there is no social order, in every time and place there will be local settings with some degree of order: For social agents is a completely natural process to create order. In second place, it is impossible to avoid that those order change. Social life reproduces itself through process that imply that it is always open to new possibilities. 


\section{References}

Aguilar, 0. (2008). La teoría del habitus y la crítica realista al conflacionismo central. Persona y Sociedad, 22 (1), 9-26.

Albin, P. S. (1998). Barriers and Bounds to Rationality. Princeton, NJ: Princeton University Press.

Archer, M. S. (1995). Realist Social Theory: The Morphogenetic Approach. Cambridge: Cambridge University Press.

Aristotle. (2009). The Nicomachean Ethics. Oxford: Oxford University Press.

Arminen, I., Segersven, O. E., \& Simonen, M. (2019). Active and latent social groups and their interactional expertise. Acta Sociologica, 62 (4), 391-405.

Atkinson, W. (2010). Phenomenological Additions to the Bourdieusian Toolbox: Two Problems for Bourdieu, Two Solutions from Schutz. Sociological Theory, 28 (1), 119.

Benzecry, C. E., Krause, M., \& Reed, I. A. (2017). Introduction: Social Theory Now. In Social theory now (pp. 1-17). Chicago, IL: Chicago University Press.

Boltanski, L. (2009). De la Critique. Paris: Gallimard.

Borgatti, S., Everett, M., \& Johnson, J. (2013). Analyzing social Networks. London: Sage.

Bourdieu, P. (1979). La Distinction. Paris: Les Éditions de Minuit. 
Bourdieu, P. (1990). The Logic of Practice. Stanford: Stanford University Press.

Bourdieu, P. (1994). Raisons pratiques. Paris: Seuil.

Bourdieu, P. (2000). Pascalian Meditations. Stanford, CA: Stanford University Press.

Bourdieu, P. (2015) Sociologie générale. París: Seuil

Brandmayr, F. (2018). Order and Conflict Theories of Science as Competing Ideologies. Social Epistemology, 32 (3), 175-195.

Çalıkan, K., \& Callon, M. (2010). Economization, part 2: a research programme for the study of markets. Economy and Society, 39 (1), 1-32.

Callon, M. (2007). What does it mean to say that economics is 'performative'? In D. MacKenzie, F. Muniesa, \& L. Siu (Eds.), Do economists make markets? On the performativity of economics (pp. 311-357). Princeton, NJ: Princeton University Press.

Castellano, C., Fortunato, S., \& Loreto, V. (2009). Statistical physics of social dynamics. Reviews of Modern Physics, 81 (2), 591-646.

Castoriadis, C. (2006). Lo que hace a Grecia 1: De Homero a Heráclito. Buenos Aires: Fondo de Cultura Económica.

Centola, D. (2018). How Behaviour Spreads. Princeton, NJ: Princeton University Press.

Centola, D., \& Macy, M. (2007). Complex Contagions and the Weakness of Long Ties. American Journal of Sociology, 113 (3), 702-734.

Chuaqui, J. (2011). Microsociología y Estructura Social Global. Santiago: LOM. 
Collins, H., \& Evans, R. (2014). Quantifying the Tacit: The Imitation Game and Social Fluency. Sociology, 48 (1), 3-19.

Correll, S. J., Ridgeway, C. L., Zuckerman, E. W., Jank, S., Jordan-Bloch, S., \& Nakagawa, S. (2017). It's the Conventional Thought That Counts. American Sociological Review, 82(2), 297-327.

Cristiano, J. L. (2011). Habitus e imaginación. Revista Mexicana de Sociología, 73 (1), 4772.

Dépelteau, F. (2008) Relational Thinking: A Critique of Co-Deterministic Theories of Structure and Agency. Sociological Theory, 26 (1): 51-73

Dépelteau, F. (2013). What is the direction of the relational turn? In C. Powell \& F. Dépelteau (Eds.), Conceptualizing relational sociology (pp. 163-185). New York: Palgrave.

Dubet, F. (1994). Sociologie de l'expérience. Paris: Seuil.

Elster, J. (1989). The Cement of Society. Cambridge: Cambridge University Press.

Epstein, J. (2007). Generative Social Science. Princeton, NJ: Princeton University Press.

Epstein, J. (2013). Agent_Zero: Toward Neurocognitive Foundations for Generative Social Science. Princeton, NJ: Princeton University Press.

Fehr, E., \& Gintis, H. (2007). Human Motivation and Social Cooperation: Experimental and Analytical Foundations. Annual Review of Sociology, 33, 43-64. 
Flyvbjerg, B. (2001). Making Social Science Matter: Why Social Inquiry Fails and How It Can Succeed Again. Cambridge: Cambridge University Press.

Flyvbjerg, B., Landman, T., \& Schram, S. (2012). Real Social Science. Cambridge: Cambridge University Press.

Frank, A. W. (2012). The feel for power games. In B. Flyvbjerg, T. Landman, \& S. Schram (Eds.), Real social science (pp. 4-65). Cambridge: Cambridge University Press.

Gerrans, P. (2005). Tacit knowledge, rule following and Pierre Bourdieu's philosophy of social science. Anthropological Theory, 5, 53-74.

Giddens, A. (1984). The Constitution of Society. Cambridge: Polity Press.

Giddens, A. (1993). The New Rules of Sociological Method (2nd ed.). Cambridge: Polity Press.

Gonnet, J. P. (2015). Durkheim, Luhmann y la delimitación del problema del orden social. Revista Mexicana de Ciencias Políticas y Sociales, 60 (225), 285-309.

Gonnet, J. P. (2018). La doble contingencia como clave para una redefinición del concepto de orden social. Estudios Sociológicos, 36 (106), 47-72.

Graham, A. C. (1989). Disputers of the Tao. Chicago, IL: Open Court.

Haun, D. B. M., Rekers, Y., \& Tomasello, M. (2014). Children conform to the behavior of peers; other great apes stick what what they know. Psychological Science, 25 (12), 2160-2167.

Hedström, P. (2005). Dissecting the Social. Cambridge: Cambridge University Press. 
Hindriks, F. (2019). Norms that Make a Difference: Social Practices and Institutions. Analyse und Kritik, 41 (1), 125-145.

Hirschman, A. O. (1992). Rival views of Market Society. Cambridge, Mass.: Harvard University Press.

Joas, H. (1992). Die Kreativität des Handelns. Frankfurt am Main: Suhrkamp.

Kant, I. (2012). Crítica del Discernimiento. Madrid: Alianza Editorial.

Kant, I. (2013). Crítica de la Razón Práctica. Madrid: Alianza Editorial.

Latour, B (2005). Reassembling the Social: An Introduction to Actor-Network-Theory. Oxford: Oxford University Press.

Luhmann, N. (1995). Social Systems. Stanford, CA: Stanford University Press.

Manzo, G. (2014). Data, Generative Models and Mechanisms. In G. Manzo (Ed.), Analytical sociology (pp. 4-52). Chichester: Wiley.

Manzo, G., Gabbriellini, S., Roux, V., M'Mbogori, F. N., \& M'Mbogori, F. N. (2018). Complex Contagions and the Diffusion of Innovations: Evidence from a Small-N Study. Journal of Archaeological Method and Theory, 25 (4), 1109-1154.

Martuccelli, D. (2013). Sociologías de la Modernidad. Santiago: LOM.

Meyer, M. (2013). Principia Rhetorica. Buenos Aires: Amorrortou.

Moatti, C. (2018). Res publica. Histoire romaine de la chose publique. Paris: Fayard. 
Moore, A. (2011). The eventfulness of social reproduction. Sociological Theory, 29 (4), 294-314.

Nieto Calleja, R. (2012). Pierre Bourdieu: Etnólogo, Sociólogo y Antropólogo. In E. la Garza Toledo \& G. Leyva (Eds.), Tratado de metodología de las ciencias sociales (pp. 469-503). Ciudad de México: Fondo de Cultura Económica.

Nussbaum, M. (2001). The fragility of goodness (Revised ed.). Cambridge: Cambridge University Press.

Parsons, T. (1949). The Structure of Social Action. Glencoe, Il: The Free Press.

Parsons, T. (1951). The Social System. Glencoe, Il: The Free Press

Rutzou, T., \& Elder-Vass, D. (2019). On Assemblages and Things: Fluidity, Stability, Causation Stories, and Formation Stories. Sociological Theory, 37 (4), 401-424.

Schegloff, E. A. (1992). Repair after Next Turn. American Journal of Sociology, 97 (5), 1295-1345.

Schegloff, E. A. (1996). Confirming Allusions. American Journal of Sociology, 102 (1), 161-216.

Schegloff. E. A. (2007) Sequence Organization in Interaction. A Primer in Conversation Analysis. Cambridge: Cambridge University Press.

Searle, J. R. (1995). The Construction of Social Reality. London: Penguin.

Seidenberg, M. S., \& Plaut, D. C. (2014). Quasiregularity and Its Discontents: The Legacy of the Past Tense Debate. Cognitive Science, 38 (6), 1190-1228. 
Sextus Empiricus. (2000). Outlines of Scepticism. Cambridge: Cambridge University Press.

Skvoretz, J. (2002). Complexity theory and models for social networks. Complexity, 8 (1), 47-55.

Swedberg, R. (2011). The Economic Sociologies of Pierre Bourdieu. Cultural Sociology, $5(1), 67-82$.

Tavory, I., \& Fine, G. A. (2020). Disruption and the theory of the interaction order. Theory and Society, 49 (3), 365-385.

Touraine, A. (2013). La Fin des Sociétés. Paris: Seuil.

van der Berg, A. (1998). Is sociological theory too grand for social mechanisms? In P. Hëdstrom \& R. Swedberg (Eds.), Social mechanisms (pp. 204-237). Cambridge: Cambridge University Press.

Voth, H.-J. (2001). Time and Work in England 1770-1830. Oxford: Clarendon Press.

White, H. C. (2008). Identity and Control (2nd ed.). Princeton, NJ: Princeton University Press.

Winch, P. (1958). The Idea of a Social Science. London: Routledge.

Wood, M. L., Stoltz, D. S., Van Ness, J., \& Taylor, M. A. (2018). Schemas and Frames. Sociological Theory, 36 (3), 244-261.

Young, H. P. (1998). Individual Strategy and Social Structure. Princeton, NJ: Princeton University Press. 